\title{
O planejamento por área do conhecimento e a formação continuada de professores: um diálogo potente no contexto de uma escola pública estadual do Espírito Santos
}

\author{
Jaqueline Oliozi' ${ }^{1}$, Geide Rosa Coelho²
}

\begin{abstract}
Resumo:
Este trabalho tem como objetivo apresentar uma síntese da pesquisa realizada em uma escola de Ensino Médio da rede pública estadual do Espírito Santo. O percurso metodológico utilizado foi o estudo de caso, e a análise dos dados produzidos foi realizada mediante a Análise Textual Discursiva. Os principais resultados da investigação apontam que o espaço-tempo do planejamento por área do conhecimento, implementado nas escolas estaduais do Espírito Santo, pode contribuir na formação continuada de professores se utilizado para a troca de conhecimentos e a partilha de experiências. Além disso, os professores potencializam esse momento à medida que dialogam sobre o currículo, os projetos interdisciplinares, o comportamento dos estudantes e outros temas que permeiam a prática docente.
\end{abstract}

Palavras-chave: Planejamento por área. Formação continuada. Trabalho coletivo.

1 Mestra em Educação pelo Programa de Pós-Graduação em Educação da Universidade Federal do Espírito Santo (UFES). Secretaria Estadual de Educação do Estado do Espírito Santo.

E-mail: jaquelineoliosi@hotmail.com

2 Professor doutor do Centro de Educação da UFES e dos Programas de Pós-Graduação em Educação e Ensino de Física da UFES.

E-mail: geidecoelho@gmail.com 


\title{
The planning by area of knowledge and teacher training: a powerful dialogue in the context of a state public school of Espírito Santo
}

\author{
Jaqueline Oliozi, Geide Rosa Coelho
}

\begin{abstract}
:
This study aims to present a synthesis of the research carried out in a public high school of Espírito Santo (Brazil). The methodological approach used was the case study, and the analysis of data produced was carried out by Text Analysis Discourse. The main results of the research showed that the planning of spacetime by each area of knowledge implemented in the state schools of Espírito Santo can contribute to teachers training if used for the exchange of knowledge and experience. In addition, teachers potentiate this experience as they dialogue about the curriculum, the interdisciplinary projects, the behavior of students and other issues that underly the teaching practice.
\end{abstract}

Keywords: Planning by area. Teachers Training. Collective work. 


\section{Introdução}

Este trabalho tem como objetivo apresentar algumas discussões referentes aos resultados da pesquisa intitulada "O Planejamento por área do conhecimento da rede pública estadual do Espírito Santo: espaço-tempo de formação continuada de professores?”, realizada em 2015, durante o Mestrado em Educação, na Universidade Federal do Espírito Santo (UFES). A pesquisa teve como objetivo central investigar se e como o planejamento da área de Ciências Humanas constitui espaço-tempo de formação continuada para professores de História da Superintendência Regional de Educação/Nova Venécia.

A motivação para realizar essa investigação deveu-se ao envolvimento da primeira autora como professora de História da rede pública estadual do Espírito Santo, em dois momentos: em 2008, durante a elaboração do documento curricular da rede pública estadual, e no período de 2011 a 2012, na implementação do planejamento por área do conhecimento.

A organização do planejamento por área do conhecimento nas escolas públicas estaduais do Espírito Santo segue a orientação da Secretaria de Estado da Educação (SEDU). Às terças-feiras planejam os professores da área de Ciências Humanas (História, Geografia, Sociologia e Filosofia); às quartas-feiras os professores da área de Ciências da Natureza e Matemática (Química, Física); e às quintas-feiras os professores da área de Códigos e Linguagens (Língua Portuguesa, Artes, Educação Física e Língua Estrangeira).

Nesse sentido, a pesquisa sobre esse espaço-tempo no interior das escolas contou com a concepção de formação continuada abordada por Nóvoa (2002, 2008, 2009a, 2009b, 2011) e Imbernón (2011), permeada pela concepção de profissionalidade e currículo em Sacristán (2008), apresentada no texto que segue.

\section{Discussões teóricas e possibilidades de diálogos sobre formação continuada de professores}

As discussões teóricas aqui apresentadas têm como objetivo estabelecer uma relação entre a concepção de formação continuada e o espaço-tempo do planejamento por área do conhecimento. A temática da formação continuada de professores tem permeado os debates das políticas educacionais, do campo acadêmico e das escolas de educação básica. A preocupação central consiste em oferecer uma formação que contribua para a resolução de situações que tangem o cotidiano do exercício da profissão. Nesse sentido, o texto das Diretrizes Curriculares Nacionais para a Formação Inicial e Continuada dos Profissionais do Magistério da Educação Básica afirma:

A Formação continuada compreende dimensões coletivas, organizacionais e profissionais, bem como o repensar do processo pedagógico, dos saberes e valores, e envolve atividades de extensão, grupos de estudo, reuniões pedagógicas, cursos, programas e ações para além da formação 
mínima exigida ao exercício do magistério na educação básica, tendo como principal finalidade a reflexão sobre a prática educacional e a busca de aperfeiçoamento técnico, pedagógico, ético e político do profissional docente (BRASIL, 2015, p. 34).

O texto traz como referência, também, o respeito ao protagonismo do professor e a um espaço-tempo que lhe permita refletir criticamente e aperfeiçoar sua prática. Nesse sentido, a formação pode ser compreendida como um processo continuado que não se restringe à preparação inicial para o exercício da profissão, nem um processo que termina com a certificação, mas que ocorre na própria dinâmica do trabalho do professor e ao longo da carreira deste profissional.

O desafio que se apresenta é pensar uma formação que ocorre no espaço-tempo contínuo, que não se dissocia e que permite uma reflexão na e sobre a prática docente. A formação permanente do professor consiste em sua capacidade de gerar conhecimento pedagógico por meio da prática educativa.

A formação terá como base uma reflexão dos sujeitos sobre sua prática docente, de modo a permitir que examinem suas teorias implícitas [...]. A orientação para esse processo de reflexão exige uma proposta crítica da intervenção educativa, uma análise da prática do ponto de vista dos pressupostos ideológicos e comportamentais subjacentes (IMBERNÓN, 2011, p. 50).

Considerando o pensamento de Nóvoa (2002) de que na análise da formação são fundamentais a pessoa e a experiência, os sujeitos-professores não constroem seus conhecimentos apenas na formação universitária. Os sujeitos-professores constroem seus saberes no decorrer de suas vidas.

Os primeiros anos do professor - que, a meu ver, são absolutamente decisivos para o futuro de cada um dos professores e para a sua integração harmoniosa na profissão - continuam ao longo de toda a vida profissional, através de práticas de formação continuada. Estas práticas de formação continuada devem ter como pólo de referência as escolas. São as escolas e os professores organizados nas suas escolas que podem decidir quais são os melhores meios, os melhores métodos e as melhores formas de assegurar esta formação continuada (NÓVOA, 2002, p. 2).

A formação passa pela reflexão na e com a profissão, unindo desenvolvimento pessoal e profissional, sendo a escola o espaço para essa reflexão. É neste espaço que são organizadas as diversas atividades que envolvem os projetos, o currículo das disciplinas, as relações dos professores com seus pares, com os estudantes e com a comunidade escolar. Defendemos que é na escola que existe a possibilidade de partilha, de troca de conhecimentos e experiências, ou seja, a possibilidade de se formar dentro da profissão.

A partir dessa troca, o professor pode teorizar sua prática e estabelecer relações de sentido que lhe permitam elaborar conhecimentos culturalmente e socialmente reconhecidos pelos seus pares. Nesse sentido, a escola é o lugar por excelência que permite ao professor esse contato com os demais docentes e com outros profissionais 
da educação que, de forma coletiva, vão atribuir significados e elaborar teorias. A escola é o lugar onde estão organizados os tempos das atividades da prática docente, sendo um desses tempos reservado ao planejamento das ações. Assim, o planejamento adquire a dimensão pedagógica por meio das relações de diálogo e de organização dos conteúdos e dos temas que os professores de cada disciplina propõem.

Pensando o planejamento como espaço-tempo de uma formação que ocorre na prática da profissão, este pode se constituir pela dimensão de partilha, de troca de experiências e de saberes. Considerando que o ofício professor se faz no exercício da profissão, o planejamento pode ganhar a dimensão de autorreflexão e de análise coletiva das práticas. De acordo com Nóvoa (2002, p. 39), “A troca de experiências e a partilha de saberes consolidam espaços de formação mútua, nos quais cada professor é chamado a desempenhar, simultaneamente o papel de formador e de formando”.

Com a mobilização de um conjunto de saberes, os professores socializam e contribuem para a transformação do próprio trabalho. De forma partilhada vão constituindo sua autonomia profissional, num processo dinâmico de relações de troca.

Ao trazer a necessidade de uma dimensão coletiva do trabalho docente, Nóvoa (2002) aponta para novos modos de organização da profissão. O desenvolvimento de uma colegialidade docente pressupõe parceria, partilha e trabalho coletivo. Ocorre mediante o estabelecimento de relações que não estão determinadas sob o aspecto administrativo, mas que se fazem no cotidiano da profissão, no rompimento com as formas individualistas de trabalho.

O conjunto de práticas do professor faz parte daquilo que Sacristán (2008) define como profissionalidade. Esse conceito refere-se àquilo que é específico da ação docente, ou seja, o conjunto de comportamentos, destrezas, atitudes e valores que constituem a especificidade de ser professor. Assim, os professores de História, reunidos na área de Ciências Humanas, vão aos poucos constituindo sua profissionalidade num movimento dinâmico no interior da escola.

\section{0 processo de investigação e as categorias emergentes}

No intuito de delimitar o percurso metodológico a pesquisa caracterizou-se como um estudo de caso. Segundo Alves-Mazzotti (2006), tal estudo refere-se a questões sobre o como e o porquê e são associadas a um dado contexto, portanto, situadas. A definição do estudo se fez ainda no intuito de aproximar-se da realidade para aprofundar aspectos específicos que esta apresenta. Isso não significa que não seja possível fazer generalizações para compreender de que forma o mesmo fenômeno ocorre em outras instâncias.

No pensamento de Laville e Dionne (1999), o pesquisador escolhe considerar um segmento para chegar a uma visão que não seja superficial e que possa, apesar de tudo, valer para o conjunto. A Superintendência Regional de Educação de Nova 
Venécia, região norte do Espírito Santo, é um campo específico de investigação que se insere em um campo maior, que é a rede estadual de ensino. A investigação em um campo específico está inter-relacionada com o que ocorre em um contexto mais amplo. Assim, os professores de História da regional Nova Venécia fazem parte de uma rede de ensino que desenvolve seu trabalho, tendo semanalmente um tempo específico destinado ao planejamento na área de Ciências Humanas.

Ao pesquisar o planejamento por área do conhecimento em um grupo específico, os resultados sinalizaram para algumas proposições que podem ser aplicáveis a outros grupos de professores da área de Ciências Humanas ou das áreas de Ciências da Natureza e Códigos e Linguagens. No intuito de preservar a identidade das instituições e dos sujeitos, serão usados nomes fictícios escolhidos pela primeira autora durante o processo de pesquisa.

Quanto ao campo de pesquisa, foi selecionada uma escola que recebeu a denominação de Escola Estadual de Ensino Médio “São Marcos”. No período de abril a setembro de 2015 foram realizados os registros em campo por meio da observação participante, da entrevista e das conversas informais. Para realização da entrevista foi selecionada uma professora de História que atua na rede desde 2010 (período em que foi implantado o planejamento por área). Os dados produzidos e analisados foram registrados durante 17 encontros semanais da área de Ciências Humanas.

A análise dos dados produzidos foi realizada utilizando a Análise Textual Discursiva. Essa perspectiva traz como pressuposto a compreensão dos fenômenos que investiga a partir de textos já existentes ou produzindo o material de análise (MORAES, 2003). Nesse caso, a pesquisa sobre o planejamento por área do conhecimento baseia-se na análise dos textos contidos nos documentos e nos textos produzidos por meio da observação participante e da entrevista, o que permitiu definir seis categorias emergentes, as quais foram elaboradas a partir das informações do corpus. A partir dos documentos já existentes e dos textos elaborados durante a pesquisa, foi possível definir quais seriam as categorias, num processo de aproximação das semelhanças reservadas ao conjunto de textos.

Mediante a análise dos registros em campo e do contexto em que cada encontro semanal foi organizado com suas singularidades, as categorias emergentes foram assim apresentadas e discutidas: (i) A organização do espaço-tempo do planejamento por área do conhecimento; (ii) A organização do espaço físico do planejamento por área do conhecimento; (iii) Os limites e as possibilidades do planejamento por área do conhecimento; (iv) O currículo e o planejamento; (v) O exercício da profissão docente em frente das ações externas e da burocracia; e (vi) A formação de professores do Ensino Médio: Pacto Nacional pelo fortalecimento do Ensino Médio. No conjunto das seis categorias é possível apresentar as principais discussões e os resultados do processo de investigação. 


\section{A organização do espaço-tempo do planejamento por área do conhecimento}

Durante o processo de implantação do planejamento por área do conhecimento, os professores atribuíram significados de acordo com suas concepções e experiências. Quando perguntada sobre como chegou a ela essa ideia do planejamento por área do conhecimento (o que ela concebia no início, quando foi implementado o planejamento por área), a professora Atena respondeu:

[...] quando se falou nessa proposta, o que eu imaginava e que chegou de fato a ser uma proposta da SEDU, mas, que depois caiu no esquecimento [...] isso chegou aqui e o que nos foi dito (foi na mesma época que aumentou a quantidade de planejamento) então, quer dizer, foi uma expectativa totalmente positiva, porque teríamos mais tempo de planejamento, e o planejamento seria feito por área. Com que intuito? [...] algumas horas seria o planejamento individual e o que seria o planejamento coletivo? Nós teríamos temas pra serem debatidos, nós teríamos discussões pra serem levantadas, uma espécie de formação cotidiana, do dia a dia.

[...] Então, por exemplo, eu me lembro que na época aqui a gente chegou a fazer uma seleção de temas que nós gostaríamos, eu tenho certeza disso, porque na época eu bati muito em nós estudarmos psicologia do adolescente [...] outro tema que nós falamos muito: a avaliação. Nós pedimos muito pra discutir avaliação [...].

Então... eu imaginava e foi falado que seria assim [...] No início os professores reclamavam muito, muito mesmo, porque os professores não encontravam tempo para as tarefas, para corrigir provas [...] e como de fato pesa [...] o que você não faz aqui, você faz em casa [...] Aí ficou de quinze em quinze dias tentando se reunir [...] aí já não era toda semana mais.

Aí hoje como é que funciona? [... ] Você tem uma hora, aquela primeira hora, você senta com o pedagogo, são as informações e as tarefas a serem cumpridas e o restante fica ali [...].

No relato da professora, ela deixa explícita a compreensão do que significa - ou pelo menos do que deveria ser - o espaço-tempo do planejamento por área do conhecimento: “[...] uma espécie de formação cotidiana, do dia a dia”. Se o planejamento por área possui a dimensão formativa, esta ocorre na cotidianidade dos professores, nos diálogos e nas experiências partilhadas a cada semana, a cada encontro. No pensamento de Imbernón (2012, p. 46), a formação de professores precisa ser uma formação no local de trabalho, onde ocorrem as situações problemáticas, “uma formação desde dentro”.

A organização do espaço-tempo do planejamento por área do conhecimento em dias da semana destinados a cada área segue a orientação da Secretaria de Estado da Educação. No entanto, a dinâmica com que essa ação acontece possui um grau de particularidade que é peculiar a cada escola e até mesmo a cada dia de planejamento. Isso revela que mesmo que haja uma orientação padronizada, os sujeitos imprimem seu jeito, suas ideias e uma forma peculiar de realizar as atividades. Revela ainda que os professores resistem a um sistema de ensino que muitas vezes os quer tornar simples cumpridores de tarefas, exercem suas capacidades de argumentação e criatividade, a fim de potencializar aquilo que é próprio da profissão: a reflexão constante. 


\section{A organização do espaço físico do planejamento por área do conhecimento}

A organização interna da escola pesquisada, no que se refere ao espaço físico, apresenta limites que interferem na realização do planejamento por área do conhecimento, como é possível verificar na fala da professora Atena:

Eu acho que hoje a escola não tem o espaço físico adequado nem para as aulas, nem para o planejamento, nem para o atendimento pedagógico, nem para o coordenador, enfim, falta espaço físico na escola. Por exemplo, no planejamento, nós precisávamos ter um espaço mais silencioso, mais próprio, apropriado para o planejamento, tendo livros... Uma sala de humanas, por exemplo, com livros, documentários, vídeos com acessibilidade ao professor e quem sabe até ao aluno.

O ambiente em que os professores realizam o planejamento é a sala dos professores. Sendo o ambiente destinado à organização dos materiais utilizados por eles, como: livros, apostilas, cadernos e outros. Uma parte do espaço é destinada aos armários. Isso significa que ao mesmo tempo que estão reunidos os professores da área de Ciências Humanas, outros professores circulam pelo ambiente. Há conversas sobre diferentes temas, ruídos constantes, brincadeiras e às vezes muita interferência na fala dos professores.

As condições físico-estruturais das instituições tem sido objeto de pesquisas. Em especial, a questão do ruído foi registrada na pesquisa realizada por Ferreira, Oliveira e Vieira (2012), que evidenciaram que em escolas do Espírito Santo o ruído foi apontado como razoável por cerca de $53 \%$ dos docentes, e cerca de $37 \%$ somam os que consideram o ruído elevado e insuportável. Esse ruído apontado na pesquisa refere-se ao da sala de aula, no entanto é perceptível no relato da professora Atena e nos gestos dos demais professores que o ruído da sala dos professores interfere no desenvolvimento das atividades de planejamento.

O espaço físico deveria fazer parte do conjunto das discussões sobre os processos de ensinar e aprender, fundamentar-se em uma epistemologia que considere a reflexão e a tomada de decisões conjunta. Pensar o planejamento por área como espaço de estudo e discussão, em um ambiente tumultuado e exposto às adversidades que interferem na ação dos professores é um desafio constante.

\section{Os limites e as possibilidades do planejamento por área do conhecimento}

O planejamento por área do conhecimento, com a organização de um dia da semana para cada área (sendo terça-feira - Ciências Humanas; quarta-feira - Ciências da Natureza; quinta-feira - Códigos e Linguagens), apresenta alguns limites e possibilidades no desenvolvimento do trabalho dos professores, como é possível verificar na fala da professora Atena:

Eu vejo como fundamental... Eu já vou começar falando da crítica que eu faço: que fica muito restrito aos grupos. Acho que nós deveríamos ter momentos em que todos os professores se 
reunissem e pudessem discutir sobre a prática da sala de aula. Mas, eu gosto muito... Por quê? É o momento em que nós compartilhamos o assunto, as práticas, como nós estamos trabalhando, as dificuldades com os alunos. Geralmente a dificuldade que um professor tem com um aluno os outros acabam tendo também, então você pode conversar sobre estratégias de como abordar aquele aluno. Mas, principalmente em relação ao conteúdo... Eu penso que tem acontecido uma troca maior entre geografia, história, sociologia e filosofia... Gostaria que fosse maior ainda, que abrangesse literatura e outras disciplinas também... Eu penso como positivo, eu gosto do planejamento por área nesse aspecto de partilha.

No relato a professora afirma que o planejamento por área é o momento de compartilhar o "assunto, as práticas, as dificuldades”. Trata-se de um espaço de discussão coletiva que poderia ser ampliado para outras disciplinas.

Essa questão da falta de tempo para o diálogo entre os educadores foi registrada na pesquisa de Oliveira (2013) como um aspecto que tensiona o trabalho com a interdisciplinaridade e com o Currículo Básico da Escola Estadual. A pesquisadora destacou como resultado que os professores conseguem organizar momentos entre as aulas para dialogar sobre os materiais, conteúdos e atividades a serem desenvolvidas junto aos alunos.

No lugar da integração, o que acontece é uma fragmentação, uma separação dos professores em áreas do conhecimento. E as áreas, com suas especificidades, dialogam entre si, porém, muitas vezes, esse diálogo poderia promover um trabalho mais integrado se disciplinas de diferentes áreas tivessem um espaço-tempo de partilha de suas práticas e de seus conhecimentos.

A professora Atena fala de uma integração maior entre as disciplinas da área de Ciências Humanas. Isso remete ao planejamento por área, avaliado por ela como positivo no sentido da partilha. Isso pode ser ilustrado utilizando o registro do diário de campo:

Neste dia os professores iniciaram uma discussão sobre os alunos da educação especial, cada um expressou aquilo que compreende sobre o trabalho que realizam:

Nas palavras da professora de Filosofia, Artemis: “Acho que tenho que mudar a forma de trabalhar com os alunos da educação especial. "Pra que colar um monte de folhas no caderno?... Preciso mudar a estratégia..."

A professora Atena afirma: “[...] Eles não vão assimilar no mesmo ritmo que os demais. Temos trabalhado atividades em que eles sejam minimamente alfabetizados...”

E continua: "Você tem que definir quais os objetivos da atividade... existem momentos que o importante é somente trabalhar a linguagem... você que precisa ter a sensibilidade de perceber o que cabe em cada momento.” (Diário de campo, 19 de maio de 2015).

O diálogo sobre a educação especial é um dos registros que revela a potência que existe no momento em que os professores estão reunidos. Ao partilhar as incertezas 
e o trabalho que cada um vem desenvolvendo junto aos estudantes da educação especial, os professores buscavam uma reciprocidade, o apoio uns dos outros. Isso mostra uma quebra no isolamento, e as decisões individuais dão lugar ao coletivo da discussão realizada no grupo.

No que se refere ao trabalho com os conteúdos das disciplinas, uma questão evidenciada é que a forma como estes estão organizados no Currículo Básico da Escola Estadual, dificultando a integração ou o desenvolvimento de um trabalho interdisciplinar. Mesmo fazendo parte de uma mesma área do conhecimento, os professores nem sempre conseguem planejar de forma coletiva e integrada suas atividades.

\section{O currículo e o planejamento}

As questões referentes ao currículo apresentam-se a todo o momento, pois o encontro semanal dos professores da área de Ciências Humanas é o espaço-tempo em que podem dialogar de forma mais próxima sobre o trabalho com o currículo.

Neste dia, após o estudo do módulo da formação de professores do Ensino Médio, as professoras Atena e Hera conversavam sobre os conteúdos que estão trabalhando com as turmas, já fazendo uma organização para o segundo trimestre. Utilizavam, para isso, do currículo prescrito, fazendo uma interlocução entre o que a história poderia trabalhar e a geografia. Temas como: Guerra Fria, Idade Média e Escravidão no Brasil fizeram parte da discussão (Diário de campo, 19 de maio de 2015).

Os professores dialogavam sobre quais conteúdos estavam desenvolvendo nas turmas e, nesse sentido, procuravam aproximá-los, porém nem sempre isso é possível. No documento curricular os conteúdos estão dispostos de forma específica, por disciplina, não considerando o trabalho nas áreas do conhecimento, apesar de assim estarem organizados. O relato da professora Atena ilustra essa questão:

[...] por exemplo, eu estou com um conteúdo que pode ser abordado também por Geografia, eu peço ajuda à colega e isso acontece. Acontece até em Literatura... Não é sempre não, mas, isso acontece. Mas, também, o currículo não ajuda [...] o currículo não casa [...] primeiro as gavetinhas... não casa nada com nada. Por que não os temas geradores? [...] por que não o aluno ir compreendendo o conhecimento como um todo? [...] os currículos são muito diferentes [...] o currículo está muito voltado pra esse conhecimento fragmentado[...].

A professora Atena revela outra concepção para o trabalho com os conteúdos das disciplinas ao mencionar os temas geradores. Essa concepção estaria pautada na proposta elaborada por Paulo Freire na década de 1950. O trabalho com temas geradores pressupõe uma visão de totalidade, de abrangência da realidade e de uma metodologia dialógica. São denominados geradores porque “[...] contém em si a possibilidade de desdobrar-se em outros tantos temas (eixos temáticos e subtemas) que, por sua vez, provocam novas tarefas que devem ser cumpridas” (FREIRE, 1987, 
p. 124). Esses temas precisam ser refletidos para que os sujeitos tomem consciência de si mesmos e do mundo.

Nesse sentido, as disciplinas sairiam do âmbito dos conhecimentos fragmentados e, juntas, comporiam uma rede de conhecimentos, tendo como referência o tema gerador. Os conteúdos das disciplinas não estariam mais presos, fixados apenas no campo da disciplina, mas manteriam uma relação dialógica com outros campos do saber.

\section{O exercício da profissão docente em frente das ações externas e da burocracia}

Durante diferentes momentos da pesquisa de campo, nos encontros semanais dos professores da área de Ciências Humanas, foi possível registrar como as tarefas burocráticas atravessam o planejamento e a organização do trabalho no interior da escola e também fora dela. Em referência à exigência do posto de trabalho, Sacristán (2008, p. 71) afirma:

A prática profissional depende de decisões individuais, mas rege-se por normas coletivas adotadas por outros professores e por regulações organizacionais. A cultura da instituição é muito importante, mas é preciso não esquecer as determinações burocráticas da organização escolar.

As determinações burocráticas traduzidas em tarefas a serem cumpridas podem sinalizar para a responsabilização dos professores frente a projetos externos ou políticas públicas que nem sempre revelam os anseios dos mesmos no exercício da profissão. Uma dessas políticas que tem se tornado cada vez mais evidente nas escolas públicas estaduais do Espírito Santo são as avaliações externas.

Há uma concentração de esforços por parte dos professores em realizar essas avaliações que se aproxima de uma naturalização desse processo no interior da escola. Dedicam parte do tempo do planejamento para a análise dos resultados que os estudantes têm apresentado nas avaliações, planejam os conteúdos das disciplinas preocupados em atender à matriz curricular e participam do processo de aplicação das provas. É todo um tempo dedicado a atividades que são acrescentadas ao trabalho que realizam.

No entanto, é perceptível uma insatisfação que se manifesta por meio de gestos e atitudes de desconforto e de rejeição a esse modelo que padroniza e compromete a singularidade do trabalho dos professores. A singularidade tem relação com aquilo que torna uma ação própria e apropriada a cada circunstância, com destaque para a originalidade que a circunda.

Se os testes aplicados a cada trimestre aos estudantes do Ensino Médio, denominado Programa de Avaliação da Educação Básica do Espírito Santo (PAEBES Tri) ${ }^{3}$, desconsideram essa singularidade, há um comprometimento do trabalho docente, do

3 Essa avaliação tem por objetivo acompanhar trimestralmente o desempenho dos estudantes do Ensino Médio. Teve início de 2015 em todas as escolas públicas estaduais do estado do Espírito Santo. 
currículo e da própria organização da escola. Aquilo que distingue, que torna original o trabalho do professor, termina por ser padronizado no conjunto das ações que chegam e que são externas à escola.

Os professores estão diante de um processo que os torna responsáveis por organizar e garantir os resultados da escola. Eles estão diante de um processo, denominado por Sacristán (2002, p. 64), de "hiper-responsabilização":

O certo é que existe no discurso pedagógico dominante uma hiper-responsabilização dos professores em relação à prática pedagógica e à qualidade do ensino, situação que reflete a realidade de um sistema escolar centrado na figura do professor como condutor visível dos processos institucionalizados de educação.

A realidade do sistema escolar que coloca o professor como principal responsável por garantir os processos educativos é a mesma que limita sua autonomia. Há uma transferência de responsabilidades e de competências. As atividades de elaboração de conhecimentos, de reflexões e de decisões por parte dos professores são substituídas por atividades de treinar, "preparar" e classificar os estudantes mediante padrões de desempenho que não são os professores que elaboram. São padrões que universalizam os conhecimentos e desconsideram o contexto social e cultural em que cada escola desenvolve suas atividades. É uma política pública que caminha em outra direção no que se refere aos conhecimentos elaborados pelos professores no próprio fazer da profissão. Nas palavras de Nóvoa (2002, p. 59):

A retórica atual sobre o profissionalismo e a autonomia dos professores é muitas vezes desmentida pela realidade, e os professores têm a sua vida quotidiana cada vez mais controlada e sujeita a lógicas administrativas e burocráticas [...]. É forçoso reconhecer que a profissionalização do saber tem contribuído para desvalorizar os saberes experienciais e as práticas dos professores.

Assim, a formação contínua pode constituir um importante espaço de ruptura, estimulando o desenvolvimento profissional dos professores por meio da valorização de conhecimentos elaborados pelos docentes e da partilha de experiências na própria escola (NÓVOA, 2002).

\section{A formação de professores do Ensino Médio: Pacto Nacional pelo fortalecimento do Ensino Médio}

Quanto à formação de professores do Ensino Médio, referente ao Pacto Nacional pelo fortalecimento do Ensino Médio, a professora Atena avalia:

Positivamente, no sentido de que toda formação é sempre bem-vinda, é sempre válida, por exemplo, com a formação você acaba de certa forma sendo obrigada a estudar, a ler, a conhecer, a se aprofundar sobre novos autores. Então você acaba tendo aquele momento ali na sua semana priorizado para o estudo. Isso é sempre positivo. Nessa formação em especial eu particularmente gostei porque ela trouxe uma abordagem questionando quem é o jovem do Ensino Médio 
atualmente. Não é mais o jovem de quando eu comecei em 1998... Então quem é esse jovem atualmente? Quais são seus desejos, o que ele espera do Ensino Médio?... e foi, assim, muito surpreendente, porque no nosso caso aqui na nossa escola nós chegamos a desenvolver uma pesquisa com eles. Uma das tarefas do curso de formação era desenvolver uma pesquisa com esses jovens, perguntando sobre essas coisas. Foi muito surpreendente, eles diziam o mesmo que nós quando éramos jovens: eles queriam casa, carro, casar, ter filhos... nada que fugisse da realidade que nos tínhamos há vinte anos atrás... achei surpreendente... E esse curso me mostrou isso. Quem são os professores? A questão da autonomia do professor, o que o professor deseja hoje... Me fez refletir muito... a questão do planejamento por área foi muito discutido, a questão das avaliações, tudo isso foi discutido com essa formação... então, nesse aspecto foi muito positivo. O que eu venho falando sempre que eu tenho visto como negativo... Não é só nesta escola, mas é um movimento que tá acontecendo em amplo espaço é que eu vejo que o professor não decide nem o que ele vai estudar. Tudo já vem de um projeto de governo estabelecido por alguém que não está na sala de aula... Nós estamos perdendo nossa autonomia, nós, professores, não estamos sendo vistos mais como competentes o suficiente pra estudar por conta própria, pra planejar por conta própria, pra não ter feitores, pra conseguir você próprio desenvolver um trabalho bom em sala de aula... Talvez até os próprios professores já compraram esse discurso, eu vejo isso no dia a dia, talvez seja mais cômodo para o professor não querer estudar, então esperar qualquer coisinha ali como formação tá bom, esperar que o pedagogo diga o que ele tem que fazer, que alguém diga como tem que ser a avaliação dele. Talvez seja mais cômodo para o professor. Mas enquanto isso está acontecendo, nós estamos perdendo espaço social cada vez mais, espaço na classe da educação. Estamos deixando de ser referência da educação. Estamos perdendo espaço dentro da sociedade. [...] Essa é minha maior angústia na educação: é o professor ser visto apenas como uma peça na escola.

Os aspectos positivos avaliados pela professora Atena estão relacionados com o ganho que essa formação trouxe, no sentido de proporcionar uma aproximação com os jovens do Ensino Médio. A pesquisa realizada pelos professores junto aos estudantes revelou as concepções, os desejos que esses jovens trazem e que a escola pode potencializar como elementos formativos. Por outro lado, ao avaliar as questões relacionadas aos professores, Atena pontua um conjunto de elementos que estão relacionados à profissão e à identidade dos professores.

Ao destacar que não são os professores que decidem o que vão estudar, mas que tudo já vem pronto, de um projeto de governo, e que os professores estão perdendo a autonomia, a professora Atena vai ao encontro do pensamento de Sacristán (2002, p. 166-167):

O professor não decide sua ação no vazio, mas no contexto da realidade de um local de trabalho, numa instituição que tem suas normas de funcionamento marcadas às vezes pela administração, pela política curricular, pelos órgãos de governo de uma escola ou pela simples tradição que se aceita sem discutir... A profissão docente não é apenas algo eminentemente pessoal e criativo, sujeito às possibilidades da formação e ao desenvolvimento do pensamento profissional autônomo dos professores, mas é exercida também num campo que pré-determina em boa parte o sentido, a direção e a instrumentação técnica de seu conteúdo. 
Assim, faz-se necessário que os professores não sejam apenas consumidores e executores, mas que sejam profissionais críticos e reflexivos de sua prática, dos materiais que utilizam e da formação que participam (NÓVOA, 2002).

Há uma necessidade pontuada por Nóvoa (2002): a construção de uma visão dos professores como profissionais reflexivos que participam das decisões do dia a dia no contexto da escola. Sendo a formação do Ensino Médio uma ação que acontece na escola, os professores deveriam decidir os conteúdos, a metodologia e a organização dessa formação.

A perda de autonomia dos professores apontada na fala da professora Atena problematiza o pensamento de Nóvoa (2009b, p. 211):

Por isso, insisto na necessidade de devolver a formação de professores aos professores, porque o reforço de processos de formação baseadas na investigação só faz sentido se eles forem construídos dentro da profissão. Enquanto forem apenas injunções do exterior, serão bem pobres as mudanças que terão lugar no interior do campo profissional docente.

A autonomia dos professores está relacionada às condições em que eles desenvolvem a profissão, ao poder que possuem de decidir e intervir nos mecanismos de organização da escola, nos currículos, nos materiais didáticos e na dinâmica do trabalho docente desenvolvido junto aos estudantes.

Hoje é possível verificar uma sobrecarga de tarefas a serem cumpridas que caracterizam o trabalho dos professores muito mais pelo aspecto administrativo do que reflexivo. Nesse sentido, a formação de professores precisa não só estar na escola, mas ser definida pela escola, pelos professores.

\section{0 planejamento por área do conhecimento constitui espaço-tempo de formação de professores?}

As ações desenvolvidas pelo grupo de professores da área de Ciências Humanas durante o planejamento por área fazem parte do exercício da profissão. Revelam os modos de fazer da profissão no sentido individual e coletivo. Nesse sentido Sacristán (2002, p. 194) afirma:

A socialização profissional produzida pelos próprios companheiros é um fator de disseminação de atitudes e crenças sobre o currículo, o conhecimento, a avaliação, os comportamentos frente aos alunos, etc. Boa parte do que são os professores como tais, quanto ao seu pensamento e a seu comportamento, se explica por mediações de socialização profissional.

Ao realizarem estudos sobre o currículo, ao discutirem projetos interdisciplinares e ao criarem possibilidades de troca de conhecimentos, entre outras ações pontuadas pelos professores durante a pesquisa de campo, estes estariam, então, vivenciando um processo de mediação, de socialização profissional. Nesse sentido o planejamento 
por área do conhecimento constitui-se em espaço-tempo que potencializa as ações dos professores e dos seus processos cotidianos de reflexão em que partilham ideias, conhecimentos e práticas desenvolvidas nas escolas.

A argumentação de que o espaço-tempo do planejamento por área do conhecimento contribui no processo de formação continuada de professores está fundamentada na forma como estes se apropriam desse momento no interior das escolas e como vão atribuindo sentido às diferentes atividades que realizam.

A forma como se organiza na escola e como está posto nos documentos não configura a dimensão formativa, entretanto os sentidos atribuídos pelos professores e a validação da escola como espaço de formação é que permite atribuir a dimensão formativa ao planejamento por área do conhecimento.

Dessa forma, o pensamento trazido por Nóvoa (2002) de que a formação de professores não se esgota em cursos de aperfeiçoamento, mas que vai se constituindo ao longo da vida e do exercício da profissão, contribui para analisar o planejamento por área do conhecimento como espaço-tempo de formação continuada. E, ainda, o movimento produzido na escola por meio da partilha de conhecimentos e experiências traz uma concepção de formação como produção coletiva. Formação não como algo pronto e acabado, mas como processo que se faz continuamente por meio das reflexões, das práticas e das decisões que impactam na profissão.

No pensamento de Imbernón (2011, p. 15), a profissão docente precisa desenvolver

a capacidade reflexiva em grupo como processo coletivo para regular as ações, os juízos e as decisões sobre o ensino, já que o mundo que nos cerca tornou-se cada vez mais complexo, e as dúvidas, a falta de certezas e a divergência são aspectos consubstanciais com que o profissional da educação deve conviver, como acontece com profissionais de qualquer outro setor.

A formação não se limita a uma mera atualização científica, pedagógica e didática (IMBERNÓN, 2011), mas ganha a dimensão de espaços de participação e reflexão que possibilitam a aprendizagem para conviver com as mudanças e incertezas do mundo atual.

Assim, reconhecer o espaço-tempo do planejamento por área do conhecimento como contribuição no processo formativo dos professores implica em: considerá-lo como espaço-tempo que está em processo constante de construção, de reflexão e que não possui o mesmo sentido para todos os docentes da rede.

Cada grupo de professores e cada escola podem atribuir sentidos diferentes para uma mesma prática. Podem tomar decisões, planejar as atividades e dialogar sobre temas pertinentes ao contexto de cada escola, de cada grupo de professores, de cada turma de estudantes. Cada escola pode apresentar uma organização própria que se traduz em diferentes dimensões de trabalho coletivo. 
A forma como foram promovidos os debates, as reações de cada professor ante as situações que se apresentavam relacionadas ao conteúdo das disciplinas, os projetos interdisciplinares, as decisões tomadas e o diálogo que se estabeleceu entre eles é algo muito singular, muito próprio de cada encontro. Isso não significa, contudo, que não haja sistematização do trabalho. Ao contrário, sempre que necessário havia uma retomada de encontros anteriores no intuito de situar os temas e de organizar outras formas de realizar as atividades planejadas.

Assim, constituído como espaço-tempo de partilha e de exercício da autonomia de professores em frente das ações que desenvolvem na profissão, o planejamento por área do conhecimento, no contexto vivenciado desta pesquisa, contribui para que continuamente e cotidianamente os professores vivenciem processos formativos.

\section{Considerações Finais}

Os principais resultados da investigação apontam que o espaço-tempo do planejamento por área do conhecimento, implementado nas escolas estaduais do Espírito Santo, pode contribuir na formação continuada de professores se utilizado para a troca de conhecimentos e a partilha de experiências. Além disso, os professores potencializam esse momento à medida que dialogam sobre o currículo, os projetos interdisciplinares, o comportamento dos estudantes e outros temas que permeiam a prática docente.

A forma como foram promovidos os debates e as reações de cada professor ante as situações que se apresentavam, relacionadas ao conteúdo das disciplinas, aos projetos interdisciplinares, às decisões tomadas e ao diálogo que se estabeleceu entre eles, é algo muito singular, muito próprio de cada encontro. Isso não significa, contudo, que não haja sistematização do trabalho. Ao contrário, sempre que necessário havia uma retomada de encontros anteriores no intuito de situar os temas e de organizar outras formas de realizar as atividades planejadas.

Assim, constituído como espaço-tempo de partilha e de exercício da autonomia de professores em frente das ações que desenvolvem na profissão, o planejamento por área do conhecimento, no contexto vivenciado, contribui para que continua e cotidianamente os professores vivenciem processos formativos.

Aqui, é preciso ainda a análise que tensiona a implementação do planejamento por área do conhecimento via Secretaria Estadual de Educação. Este se fez na forma da lei e foi validado pelas escolas, no entanto é preciso de forma criteriosa dizer que nesse espaço-tempo ocorrem diálogos, trocas e elaboração de conhecimentos sobre currículo, projetos, avaliações, comportamento dos estudantes, educação especial e outros temas, que a ampliação desse tempo ainda não atende. Isso acontece principalmente porque a ampliação desse tempo trouxe outras exigências. Quando os professores realizam as atividades coletivas, precisam levar para casa as atividades individuais, como: o preenchimento de pautas, a correção dos trabalhos e a avaliações dos estudantes e, às 
vezes, até a elaboração dos planos de aula individuais que os docentes não conseguem realizar na escola. Ocorre o que Nóvoa (2002) denomina regulação da atividade docente por meio de um conjunto de tarefas que o professor precisa realizar em um tempo reduzido.

Em cada escola e em cada grupo de professores existe uma forma muito singular de organização dos encontros por área do conhecimento, o que evidencia uma pluralidade de experiências que esta pesquisa não abarcou. Há necessidade de que estudos sejam realizados em outras escolas e em outros grupos de professores para aprofundar os conceitos aqui apresentados e a concepção de formação continuada como troca e partilha de conhecimentos e experiências que tem a escola como local de referência.

\section{Referências}

ALVES-MAZZOTTI, Alda Judith. Usos e abusos dos estudos de caso. Cadernos de Pesquisa, v. 36, n. 129, set./dez. 2006.

BRASIL. MEC/Conselho Nacional de Educação. Diretrizes Curriculares Nacionais para a Formação Inicial e Continuada dos Profissionais do Magistério da Educação Básica. Diário oficial da União, Brasília, 2015.

ESPIRITO SANTO. Secretaria da Educação. Currículo Básico da Escola Estadual: Guia de Implementação. Vitória: SEDU, 2009.

FERREIRA, Eliza Bartolozzi; OLIVEIRA, Dalila Andrade; VIEIRA, Lívia Fraga (Org.). O Trabalho Docente na Educação Básica no Espírito Santo. Belo Horizonte: Fino Traço, 2012. p. 33.

FREIRE, Paulo. Pedagogia do Oprimido. Rio de Janeiro: Paz e Terra, 1987.

IMBERNÓN, Francisco. Formação Docente e profissional: formar-se para a mudança e a incerteza. 9. ed. São Paulo: Cortez Editora, 2011.

IMBERNÓN, Francisco. Formação permanente e carreira docente. Revista de Ciências Humanas, v. 13, n. 20. p. 45-50, jun. 2012. 
LAVILLE, C.; DIONNE, J. A Construção do Saber: Manual de Metodologia da Pesquisa em Ciências Humanas. Belo Horizonte: Editora UFMG, 1999.

MORAES, Roque. Uma Tempestade de Luz: A compreensão possibilitada pela Análise Textual Discursiva. Ciência e Educação, v. 9, n. 2, p. 191-211, 2003.

NÓVOA, Antônio. Profissão Professor. Porto: Ed. Porto, 2008.

NÓVOA, Antônio. Formação de Professores e Trabalho Pedagógico. Lisboa: Ed. Educa, 2002

NÓVOA, Antônio. Professores: Imagens do Futuro Presente. Lisboa: Ed. Educa, 2009a.

NÓVOA, Antônio. Para uma Formação de Professores construída dentro da Profissão. Revista de Educação, Universidade de Lisboa, n. 350, p. 203-218, set./dez. 2009b.

NÓVOA, Antônio. O Regresso dos professores. Lisboa: Ed. Educa, 2011.

SACRISTÁN, J. Gimeno. O Currículo: uma reflexão sobre a prática. 3. ed. Porto Alegre: Artmed, 2002.

SACRISTÁN, J. Gimeno. Consciência e ação sobre a prática como libertação profissional dos professores. In: NÓVOA, Antônio. Profissão Professor. Porto: Ed. Porto, 2008. p. 63-91.

OLIVEIRA, Gabriela Freire de. O planejamento por área de conhecimento e a interdisciplinaridade no cotidiano das escolas capixabas. Espaço do Currículo, v. 6, n. 1, p. 95-106, jan./abr. 2013. 